\title{
PREVENTING OPPORTUNISTIC INFECTIONS AMONG HUMAN IMMUNODEFICIENCY VIRUS-INFECTED ADULTS IN AFRICAN COUNTRIES
}

\author{
ALISON D. GRANT, JONATHAN E. KAPLAN, AND KEVIN M. DE COCK \\ Clinical Research Unit, London School of Hygiene and Tropical Medicine, London, United Kingdom; Division of HIV/AIDS \\ Prevention, Centers for Disease Control and Prevention, Atlanta, Georgia; Centers for Disease Control and Prevention,
} Nairobi, Kenya

\begin{abstract}
The burden of human immunodeficiency virus (HIV)-related disease in sub-Saharan Africa continues to increase; providing adequate care for the huge number of people affected is a daunting task, especially given the limited resources available. Recent studies have shown that low-cost regimens can prevent some of the most important causes of HIV-related disease in African countries. Isoniazid preventive therapy can reduce the incidence of tuberculosis; priorities are to seek opportunities for implementation, to assess effectiveness under operational conditions, and to monitor its effect on resistance patterns. Cotrimoxazole was shown to be highly effective in reducing morbidity and mortality among individuals with symptomatic HIV disease in Côte d'Ivoire, and should be implemented where it is likely to be of benefit. Pneumococcal polysaccharide vaccine was disappointingly ineffective among HIV-infected Ugandan adults, but newer conjugate vaccines are becoming available that should be investigated. The benefit of these preventive regimens to the individual may be modest when compared with the effect of antiretroviral therapy. However, simple preventive therapies could reach a much wider population than is immediately feasible for expensive and complex antiretroviral regimens, and thus have the potential for substantial benefit at the population level. The availability of effective and affordable regimens to prevent HIV-related disease may also encourage people to seek HIV testing, combat denial, and help overcome the sense of powerlessness in countries where the HIV epidemic has hit hardest.
\end{abstract}

\section{INTRODUCTION}

The number of people estimated to be currently living with human immunodeficiency virus (HIV) infection worldwide continues to increase. The great majority of HIV-infected people live in developing countries; of the 36.1 million people estimated to be living with HIV/acquired immunodeficiency syndrome (AIDS) at the end of 2000, more than $70 \%$ were in countries in sub-Saharan Africa. ${ }^{1}$

Providing care for HIV-infected people in low-income countries is a daunting task. Most HIV-infected people living in sub-Saharan Africa do not seek care until they have advanced disease ${ }^{2,3}$ and their mortality in hospital is high. ${ }^{2}$ However, many of the major HIV-related diseases in African countries are both treatable and potentially preventable with relatively inexpensive drugs. Several recently-published studies from developing countries demonstrate that HIV-related disease can be prevented by such regimens.

Updating earlier work, ${ }^{4}$ we review published literature concerning prevention of HIV-related opportunistic infections among adults in African countries. We summarize current knowledge, suggest what preventive treatments should be implemented, and what further research is needed.

\section{OVERVIEW OF HIV-RELATED OPPORTUNISTIC INFECTIONS IN} AFRICAN COUNTRIES

Spectrum of disease. There are important geographic differences in the spectrum of HIV-related disease., ${ }^{4,5}$ While HIV-related disease in industrialized countries is well-described, relatively few published studies describe the causes of HIV-related disease in African countries. Facilities required to confirm the diagnosis of many HIV-related diseases are not affordable in many of the countries with the greatest burden of disease, and infrastructure for surveillance of HIVrelated disease is lacking. The information available comes from a small number of published studies, most of which are cross-sectional in design.

Table 1 shows the spectrum of HIV-related disease in four African countries. Problems arise in comparing these studies directly since the prevalence of specific conditions is affected by referral patterns, the study population (HIV clinic outpatients in South Africa, hospitalized patients elsewhere), the criteria for HIV testing (a systematic sample of all admissions in Côte d'Ivoire and Kenya, only patients with suspected HIV disease in Ethiopia), the diagnostic methods, and the diseases reported (World Health Organization [WHO] stage 3- and 4-defining conditions in Ethiopia, and only WHO stage 4 conditions [Appendix 1] in South Africa). For example, the apparent difference in the prevalence of bacteremia, a major cause of HIV-related hospital admission in Côte d'Ivoire and Kenya but not reported from Ethiopia or South Africa, may be primarily because blood cultures were done routinely in the Côte d'Ivoire and Kenya studies. Another potential bias is that patients at the South African clinic were routinely prescribed cotrimoxazole preventive therapy if their CD4 count decreased below $200 \times 10^{6} / \mathrm{L}$.

Tuberculosis (TB) is clearly the most important severe HIV-related disease in African countries; TB and bacterial diseases were the major causes of HIV-related disease in Côte d'Ivoire, Ethiopia, and Kenya. South Africa has a more "western" spectrum of disease, although the spectrum varies by ethnic group. In particular, TB was the most common diagnosis among black and mixed race individuals, whereas Pneumocystis carinii pneumonia (PCP) was most common among white individuals.

Studies investigating the cause of bloodstream infections among HIV-infected individuals admitted to hospital in African countries are summarized in Table 2. Nontyphoid salmonellae are consistently the most common organisms identified; Streptococcus pneumoniae and Escherichia coli are also common. The prevalence of Cryptococcus neoformans 
TABLE 1

Major causes of human immunodeficiency virus (HIV)-related disease in Côte d'Ivoire, South Africa, Kenya, and Ethiopia

\begin{tabular}{|c|c|c|c|c|c|c|c|}
\hline \multirow{3}{*}{ Population } & \multirow{3}{*}{$\begin{array}{c}\text { Côte d'Ivoire }^{5} \\
\text { HIV + hospitalized } \\
\text { patients* }\end{array}$} & \multicolumn{4}{|c|}{ South Africa ${ }^{6}$} & \multirow{3}{*}{$\begin{array}{c}\text { Kenya }^{7,8} \\
\text { HIV }+ \text { medical } \\
\text { admissions }\end{array}$} & \multirow{3}{*}{$\begin{array}{c}\text { Ethiopia }^{3} \\
\text { Hospitalized patients } \\
\text { with suspected AIDS } \dagger\end{array}$} \\
\hline & & \multicolumn{4}{|c|}{$\begin{array}{l}\text { HIV + clinic attenders, WHO } \\
\text { stage IV }\end{array}$} & & \\
\hline & & Total & White $\div$ & Black $\ddagger$ & Mixed race $\neq$ & & \\
\hline No. of HIV + patients & 349 & 342 & & & & 95 & 79 \\
\hline Tuberculosis & $28 \%$ & $30 \% \S$ & $12 \% \S$ & $51 \% \S$ & $29 \% \S$ & $18 \%$ & $51 \% \S$ \\
\hline Bacteremia & $18 \%$ & - & & & & $26 \%$ & - \\
\hline HIV wasting & $11 \%$ & $11 \%$ & $13 \%$ & $5 \%$ & $15 \%$ & - & $34 \%$ \\
\hline Meningitis & $10 \%$ & - & & & & - & - \\
\hline Isosporiasis & $7 \%$ & - & & & & - & - \\
\hline Bacterial pneumonia & $6 \%$ & - & & & & $16 \%$ I & $13 \% \#$ \\
\hline Cerebral toxoplasmosis & $6 \%$ & $3 \%$ & $1 \%$ & $2 \%$ & $4 \%$ & - & $6 \%$ \\
\hline Bacterial enteritis & $5 \%$ & - & & & & - & - \\
\hline Nonspecific diarrhea & $5 \%$ & - & & & & $15 \%$ & - \\
\hline Esophageal candidiasis & $3 \%$ & $17 \%$ & $18 \%$ & $13 \%$ & $20 \%$ & - & $10 \%$ \\
\hline Cryptococcosis & $2 \%$ & $9 \%$ & $7 \%$ & $3 \%$ & $7 \%$ & $1 \%$ & - \\
\hline Cytomegalovirus & 0 & $9 \%$ & $13 \%$ & $2 \%$ & 0 & - & - \\
\hline Kaposi's sarcoma & $1 \%$ & $18 \%$ & $22 \%$ & $14 \%$ & $14 \%$ & $2 \%$ & - \\
\hline Pneumocystis pneumonia & 0 & $22 \%$ & $34 \%$ & $8 \%$ & $18 \%$ & - & $1 \%$ \\
\hline HIV encephalopathy & 0 & $14 \%$ & $23 \%$ & $2 \%$ & $11 \%$ & - & $8 \%$ \\
\hline Chronic herpes simplex & 0 & $13 \%$ & $15 \%$ & $10 \%$ & $10 \%$ & - & $3 \%$ \\
\hline
\end{tabular}

in blood cultures varies widely between studies; this may be partly due to differences in laboratory methods.

Cryptococcal disease is increasingly described as an important cause of HIV-related disease in African countries; it was reported to be the third most common AIDS-defining opportunistic infection in Rwanda, ${ }^{13}$ and cryptococcal meningitis was the most common cause of meningitis among hospitalized adults in Harare, Zimbabwe. ${ }^{14}$ Since effective treatment is rarely affordable, cryptococcal disease may be a more important cause of mortality than of morbidity; it was the third most common cause of death in a cohort of HIV-infected people in Uganda ${ }^{15}$ and the most common cause of death among HIV-infected mineworkers in South Africa (Corbett EL and others, unpublished data). Cryptococcal disease may be a lesser problem in West Africa, although there are few comparable studies; in Côte d'Ivoire, it was the cause of death in only $3 \%$ of HIV-infected patients. ${ }^{16}$

Level of immunosuppression at which severe disease occurs. Since CD4 counts are rarely available in African countries, there is little information about the level of immunosuppression at which HIV-related disease occurs. Existing data, however, suggest that most HIV-infected individuals admitted to hospital have severe immunosuppression. The median CD4 count among HIV-infected patients admitted to the infectious diseases and respiratory medicine wards in Abidjan, Côte d'Ivoire was 87 and $167 \times 10^{6} / \mathrm{L}$, respectively, ${ }^{2,9}$ compared with $83 \times 10^{6} / \mathrm{L}$ in Addis Ababa, Ethiopia. $^{3}$

Improving the outcome for HIV-infected individuals with advanced disease under these circumstances is likely to be difficult. It would require patients to seek care earlier in their illness, diagnostic facilities to be accessible, and treatment to be affordable; although many of these diseases can be treated, the cost (of, for example, antifungal therapy) is currently prohibitive, particularly since long-term secondary prophylaxis is often required.

Conclusions. Many important causes of HIV-related disease in African countries are preventable. Although major improvements in survival are unlikely without combination antiretroviral therapy, ${ }^{17}$ relatively simple and inexpensive preventive therapy is an attractive option for HIV-infected people. HIV-infected individuals would need to be identified earlier in the course of disease for such preventive therapy to be effective; wider uptake of voluntary counseling and testing could achieve this.

The major potential targets for prevention in African countries are TB, bacterial infections including pneumococcal disease and nontyphoid salmonella, toxoplasmosis, and, in some areas, cryptococcal disease. Studies that have evaluated preventive regimens relevant to HIV-infected people in African countries are discussed in the following sections.

\section{PREVENTING TUBERCULOSIS}

What we know. A number of trials have evaluated the efficacy of primary preventive therapy against TB among HIV-infected individuals (Table 3 ). In all the trials, preventive therapy reduced the incidence of TB among HIV-infected people with a positive tuberculin skin test. However, the results were not always statistically significant; in some trials this was probably because of low statistical power due to a small number of participants with positive tuberculin tests. In the two meta-analyses, the effect in people with positive tuberculin tests was both statistically and clinically significant, with a reduction in the risk of TB by $60 \%$ and 
TABLE 2

Cause of bacteremia among human immunodeficiency virus (HIV)-infected patients admitted to hospitals in five African countries

\begin{tabular}{|c|c|c|c|c|c|c|}
\hline Country & Côte d'Ivoire ${ }^{2,9}$ & Tanzania $^{10}$ & Uganda $^{11}$ & Côte d'Ivoire ${ }^{12}$ & Rwanda $\dagger$ & Kenya $^{7}$ \\
\hline Population & $\begin{array}{l}\text { Acute medical } \\
\text { admissions } \$\end{array}$ & $\begin{array}{l}\text { Febrile medical } \\
\text { admissions }\end{array}$ & $\begin{array}{l}\text { Febrile medical } \\
\text { admissions }\end{array}$ & $\begin{array}{l}\text { Infectious diseases } \\
\text { admissions }\end{array}$ & $\begin{array}{l}\text { Febrile medical } \\
\text { admissions }\end{array}$ & $\begin{array}{l}\text { Acute medical } \\
\text { admissions }\end{array}$ \\
\hline No. HIV-infected patients & 349 & 282 & 227 & 202 & 163 & 95 \\
\hline \multicolumn{7}{|c|}{ No. $(\%)$ with blood stream infections, excluding mycobacteria§ } \\
\hline & $63(18 \%)$ & $118(42 \%)$ & $61(27 \%)$ & $39(19 \%)$ & $52(32 \%)$ & $26(27 \%)$ \\
\hline \multicolumn{7}{|c|}{ Organisms identified ( $\%$ of total with blood stream infection) } \\
\hline Nontyphoid salmonella & $56 \%$ & $23(36 \%)$ & $13(41 \%)$ & $16(41 \%)$ & $10(19 \%)$ & $10(38 \%)$ \\
\hline Streptococcus pneumoniae & $17 \%$ & $6(9 \%)$ & $11(34 \%)$ & $3(8 \%)$ & $12(23 \%)$ & $7(27 \%)$ \\
\hline Escherichia coli & $17 \%$ & $7(11 \%)$ & $2(6 \%)$ & $4(10 \%)$ & - & $2(8 \%)$ \\
\hline Cryptococcus neoformans & $0 \%$ & $10(16 \%)$ & 0 & $5(13 \%)$ & $13(25 \%)$ & $1(4 \%)$ \\
\hline Other & $11 \%$ & $18(28 \%)$ & $6(19 \%)$ & $12(31 \%)$ & $17(33 \%)$ & $6(23 \%)$ \\
\hline No. $(\%)$ with mycobacteremia & - & $57(20 \%)$ & $30(13 \%)$ & $10(5 \%)$ & $1(0.5 \%)$ & - \\
\hline
\end{tabular}

No. (\%) with mycobacteremia

$-=$ data not available

Taelman and others, unpublished data.

Infectious diseases and respiratory wards combined; a weighted average was used to allow for unequal sampling; therefore, absolute numbers are not given.

$\$$ Clinically important organisms. Since cultures for mycobacteria were not done in all studies, to facilitate comparison, mycobacterial isolates have been excluded from this analysis, but fungi are included. Some individuals had more than one organism; thus, totals may exceed $100 \%$.

$68 \%$, respectively. Among individuals who had either a negative tuberculin test or were anergic, TB preventive therapy had no significant protective effect in any of the studies or meta-analyses. Most of the trials that evaluated the effect of preventive therapy irrespective of tuberculin test result found that preventive therapy protected against TB (Table 3). In support of these findings, the meta-analyses both produced statistically significant results among all individuals regard- less of tuberculin status, with pooled estimates of reduction in TB incidence of $43 \%{ }^{23}$ and $42 \% .^{24}$

Only one trial ${ }^{18}$ showed a significant reduction in mortality rates in the intervention group. Most studies were not designed to examine this question and had inadequate statistical power to detect a significant effect on mortality rates. In the meta-analyses, the study of Wilkinson and others found a pooled estimate for a reduced risk of death of $27 \%$

TABLE 3

Summary of randomized, placebo-controlled trials and meta-analyses of tuberculosis preventive therapy in human immunodeficiency virusinfected people

\begin{tabular}{|c|c|c|c|c|c|c|c|}
\hline \multirow[b]{2}{*}{ Study } & \multirow[b]{2}{*}{ Researcher } & \multirow[b]{2}{*}{ Country } & \multirow[b]{2}{*}{ Regimen* } & \multicolumn{4}{|c|}{$\begin{array}{l}\text { Unadjusted relative risk of tuberculosis } \\
\text { Point estimate (95\% confidence interval) }\end{array}$} \\
\hline & & & & PPD+ & PPD- & Anergic & All \\
\hline \multicolumn{8}{|c|}{ Randomized controlled trials } \\
\hline$\overline{1}$ & Pape $^{18}$ & Haiti & $12 \mathrm{H}$ & $\begin{array}{c}0.17 \\
(0.03-0.83)\end{array}$ & $\begin{array}{c}0.56 \\
(0.11-2.5)\end{array}$ & - & $\begin{array}{c}0.29 \\
(0.09-0.9)\end{array}$ \\
\hline 2 & Valdespino & Mexico & $6 \mathrm{H}$ & $\begin{array}{l}0.19 \\
(0-13.72)\end{array}$ & - & - & - \\
\hline 3 & Wadhawan§ & Zambia & $6 \mathrm{H}$ & - & - & - & $\begin{array}{c}0.4 \\
(0.2-0.82)\end{array}$ \\
\hline 4 & Hawken $^{19}$ & Kenya & $6 \mathrm{H}$ & $\begin{array}{c}0.70 \mathrm{II} \\
(0.29-1.78)\end{array}$ & $\begin{array}{c}1.20 \\
(0.52-2.46)\end{array}$ & - & $\begin{array}{c}1.11 \\
(0.64-1.98)\end{array}$ \\
\hline \multirow[t]{3}{*}{5} & Whalen $^{20}$ & Uganda & $6 \mathrm{H}$ & $\begin{array}{c}0.33 \\
(0.14-0.77)\end{array}$ & - & $\begin{array}{c}0.83 \\
(0.34-2.04)\end{array}$ & - \\
\hline & & & $3 \mathrm{RH}$ & $\begin{array}{c}0.40 \\
(0.18-0.86)\end{array}$ & - & - & - \\
\hline & & & 3RHZ & $\begin{array}{c}0.51 \\
(0.24-1.08)\end{array}$ & - & - & - \\
\hline 6 & Gordin $^{21}$ & United States & $6 \mathrm{H}$ & - & - & $\begin{array}{c}0.48 \\
(0.12-1.91)\end{array}$ & - \\
\hline \multirow[t]{3}{*}{7} & Mwinga $^{22}$ & Zambia & $6 \mathrm{H}_{2}$ & $\begin{array}{c}0.25 \mathscr{I} \\
(0.05-1.14)\end{array}$ & $\begin{array}{c}0.86 \amalg \\
(0.31-2.38)\end{array}$ & - & $\begin{array}{c}0.62 \\
(0.38-0.99)\end{array}$ \\
\hline & & & $3 \mathrm{RZ}_{2}$ & $\begin{array}{c}0.3 \rrbracket \\
(0.06-1.4)\end{array}$ & $\begin{array}{c}1.25 \mathrm{I} \\
(0.49-3.16)\end{array}$ & & $\begin{array}{c}0.58 \\
(0.35-0.95)\end{array}$ \\
\hline & & & Combined & $\begin{array}{c}0.27 \\
(0.08-0.87)\end{array}$ & $\begin{array}{c}1.06 \\
(0.46-2.46)\end{array}$ & & \\
\hline \multicolumn{2}{|c|}{ Meta-analyses } & \multicolumn{6}{|c|}{ Studies included } \\
\hline & Wilkinson $^{23}$ & \multicolumn{2}{|c|}{$1,4,5,6$} & $\begin{array}{c}0.32 \\
(0.19-0.51)\end{array}$ & $\begin{array}{c}0.82 \\
(0.50-1.36)\end{array}$ & - & $\begin{array}{c}0.57 \\
(0.41-0.79)\end{array}$ \\
\hline & Bucher $^{24}$ & \multicolumn{2}{|c|}{ 1-7 (isoniazid arms only) } & $\begin{array}{c}0.40 \\
(0.24-0.65)\end{array}$ & $\begin{array}{c}0.84 \\
(0.54-1.30)\end{array}$ & - & $\begin{array}{c}0.58 \\
(0.43-0.8)\end{array}$ \\
\hline
\end{tabular}

* Drug regimens: $\mathrm{H}=$ isoniazid; $\mathrm{R}=$ rifampicin; $\mathrm{Z}=$ pyrazinamide. The prefix indicates the duration of the regimen in months; the subscript indicates the number of doses per week if the regimen was intermittent rather than daily. PPD $+=$ positive tuberculin skin test; PPD- = negative tuberculin skin test. - Data from Bucher and others. ${ }^{24}$

§ Wadhawan D and others, unpublished data.
II Data from Hawken and Muhindi. 25 
(95\% confidence interval $[\mathrm{CI}]=5-43 \%)$ among the subgroup with a positive tuberculin test, but no significant effect on mortality rates for the entire group, ${ }^{23}$ while the study of Bucher and others found no effect on mortality rates, either overall or in the tuberculin-positive subgroup. ${ }^{24}$

What we don't know. Who should receive TB preventive therapy? Preventive therapy is only of proven benefit to HIV-infected people with a positive result on a tuberculin skin test, and so preventive therapy should ideally be restricted to this group. However, performing tuberculin tests in low-income countries is not easy; staff need special training, tuberculin is not always available, individuals must return to have their tests read at $48 \mathrm{hr}$, and nosocomial transmission of HIV and other pathogens may occur. In populations where the prevalence of tuberculous infection or the risk of new infection is high, preventive therapy is likely to be beneficial and should be implemented even if tuberculin tests cannot be carried out. WHO and the Joint United Nations Programme on HIV/AIDS (UNAIDS) recommend that if tuberculin skin testing is not feasible, HIV-infected individuals may be considered for preventive therapy if the prevalence of tuberculous infection in the population is more than $30 \%$, or if they are health care workers, household contacts of TB patients, prisoners, miners, or members of other groups at high risk of acquiring $\mathrm{TB} .{ }^{26}$

How long should preventive therapy be given? In the preHIV era, studies in immunocompetent individuals suggested that the optimum duration of isoniazid preventive therapy for maximum reduction of TB incidence was 12 months. ${ }^{27}$ However, on the basis of cost-effectiveness and the risk of hepatitis, six months of isoniazid was considered preferable. ${ }^{28}$ The Centers for Disease Control and Prevention and American Thoracic Society guidelines now recommend nine months of isoniazid for both HIV-infected and uninfected individuals. ${ }^{29}$ In the early studies, the rationale for preventive therapy was to eradicate latent tuberculous infection. ${ }^{27}$ However with the advent of the HIV pandemic, the importance of recent infection as well as reactivation of latent infection in HIV-infected people is now appreciated. ${ }^{30} \mathrm{In}$ recent studies among South African gold miners, most TB was attributed to ongoing transmission, ${ }^{31}$ and reinfection was more frequent than relapse as a cause of recurrent TB among HIVinfected gold miners (Sonnenburg P and others, unpublished data). Where newly acquired infection is an important contributor to active TB, a longer or even indefinite course of preventive therapy may be more effective.

Studies of TB preventive therapy among HIV-infected individuals support the idea that six months may be too short. In two of these studies, the efficacy of preventive therapy decreased with time after preventive treatment was stopped ${ }^{22}$ (Wadhawan D and others, unpublished data) such that one year after completing preventive therapy, the incidence of TB in the treated groups was similar to that in the placebo group. $^{22}$ In Haiti, where twice a week isoniazid for six months was compared with twice a week rifampicin plus pyrazinamide for three months, the risk of TB was significantly lower in the group receiving six months of isoniazid during the first 10 months of the trial. ${ }^{32}$ Among all placebocontrolled trials of preventive therapy, the maximum protective effect found was in the trial evaluating 12 months of isoniazid; ${ }^{18}$ all the other trials evaluated shorter regimens.
In summary, TB preventive therapy may be more effective if given for longer than six months, or even indefinitely, but evidence of superiority over a six-month regimen is lacking. Longer or indefinite preventive therapy regimens might be associated with reduced adherence, and this would need to be monitored.

What is the effect of preventive therapy on antituberculous drug resistance? There are concerns that the widespread introduction of preventive therapy may increase the prevalence of drug-resistance among isolates of Mycobacterium tuberculosis, although this is not supported by evidence from trials conducted in the pre-HIV era. ${ }^{33}$ Theoretically, the use of isoniazid as a single agent in preventive therapy in individuals with latent infection with an isoniazid-resistant organism would be ineffective but would not promote drug resistance. However, isoniazid monotherapy given to individuals with undetected active TB might result in acquired resistance to isoniazid. This is of particular concern among HIV-infected people in whom active TB may be prevalent ${ }^{34}$ and difficult to diagnose. It is therefore important to identify individuals with active TB and ensure that they receive full antituberculous treatment.

An alternative approach would be to use preventive therapy regimens with more than one drug, which would resolve the problem of persons with active disease unintentionally receiving isoniazid monotherapy. However, multidrug preventive therapy regimens are expensive, and if unsupervised preventive therapy regimens including rifampicin were introduced, resistance to this key antituberculous agent might be promoted. It will be important to monitor the effect of preventive therapy on antituberculous drug resistance.

Another question concerns what regimen is appropriate in populations where there is already a high prevalence of resistance to isoniazid and other antituberculous drugs. Few data from African countries document the prevalence of antituberculous drug resistance, but evidence suggests that there is already significant primary resistance in several countries. For example, primary resistance to at least isoniazid and rifampicin was reported among $5.3 \%$ patients in Côte d'Ivoire during the period 1995-1996. ${ }^{35}$ Where the prevalence of primary isoniazid resistance is high, preventive therapy with more than one agent may be considered, but this must be balanced against the risks of promoting rifampicin resistance if unsupervised rifampicin-containing regimens are used.

What is the best way to exclude active tuberculosis? It is important to ensure that individuals with active TB do not receive isoniazid monotherapy. The best way to screen people to detect those with active disease is not clear; studies are needed to determine whether a symptom screen is adequate or whether radiologic and microbiologic investigations are required. The need for a screening system with adequate sensitivity to detect active disease needs to be balanced against the expense of the investigations required. In addition, a complex screening system requiring multiple visits may deter people from starting preventive therapy (Ayles $\mathrm{H}$ and others, unpublished data).

Impact and cost-effectiveness of tuberculosis preventive therapy. Since TB preventive therapy has not yet been widely introduced, there are no data on its effectiveness and impact on TB control; these will need to be evaluated. Mod- 
TABLE 4

Comparison of two studies of the efficacy of cotrimoxazole among symptomatic human immunodeficiency virus-infected people in Abidjan, Côte d'Ivoire*

\begin{tabular}{|c|c|c|c|c|}
\hline Study & \multirow{2}{*}{\multicolumn{2}{|c|}{$\begin{array}{l}\text { Anglaret and others }{ }^{45} \\
\text { Health center } \\
\text { attenders, } \\
\text { WHO stage } 2 / 3\end{array}$}} & \multicolumn{2}{|l|}{ Wiktor and others ${ }^{44}$} \\
\hline \multirow[t]{2}{*}{ Population } & & & $\begin{array}{l}\text { Newly diagnosed TB } \\
\text { patients (i.e., at least } \\
\text { WHO stage 3) }\end{array}$ & \\
\hline & Cotrimoxazole & Placebo & Cotrimoxazole & Placebo \\
\hline \multicolumn{5}{|l|}{ Population characteristics } \\
\hline Number of participants & 271 & 270 & 386 & 385 \\
\hline Total follow-up time (person years) & 190 & 157 & 366 & 333 \\
\hline Follow up duration $†$ (months) & 9.6 & 9.5 & 10.8 & 10.1 \\
\hline Baseline CD4 level $\dagger\left(\times 10^{6} / \mathrm{L}\right)$ & 322 & 331 & 311 & 325 \\
\hline \multicolumn{5}{|l|}{ Main outcome measures } \\
\hline No. of hospitalizations & 79 & 162 & 29 & 47 \\
\hline Hospitalization rate (per 100 person years) & 41.6 & $103.2 \ddagger$ & 8.2 & 15.0 \\
\hline Rate ratio for hospitalization & (not given) & & $0.57(0.36-0.90)$ & \\
\hline Deaths & 41 & 46 & 51 & 86 \\
\hline Death rate (per 100 person years) & 21.2 & 29.3 & 13.8 & 25.4 \\
\hline Mortality hazard ratio & $0.87(0.57-1.32)$ & & $0.54(0.38-0.77)$ & \\
\hline Severe event hazard ratio & $0.57(0.43-0.75)$ & & & \\
\hline
\end{tabular}

eling exercises suggest that TB preventive therapy is likely to be cost-effective..$^{36,37}$ However, all such models are highly dependent on their baseline assumptions, and it will be important to confirm these estimates with real data.

Is secondary preventive therapy effective? Little work has been done to evaluate secondary preventive therapy for HIVinfected individuals who have previously been treated for an episode of TB. In a double-blind trial in Zaire, HIV-infected patients completing short course chemotherapy for TB were randomly assigned to receive an additional six months of twice a week rifampicin plus isoniazid or placebo. The intervention group had a significantly lower rate of TB recurrence $(1.9 \%$ versus $9 \% ; P<0.01)$ although losses to followup were high. ${ }^{38}$ In an open trial among HIV-infected adults who had completed treatment for pulmonary TB in Abidjan, Côte d'Ivoire, the incidence of TB in the isoniazid plus sulphadoxine-pyrimethamine group versus the untreated group was 2.1 versus 7.0 per 100 person years (relative risk [RR] $=0.3,95 \% \mathrm{CI}=0.09-0.94) .{ }^{39}$ In a study in Haiti, individuals completing short course TB treatment were randomly assigned to receive 12 months of isoniazid as post-treatment prophylaxis or placebo. ${ }^{40}$ Among HIV-infected participants, the incidence of TB was lower in the group receiving isoniazid compared with controls ( 1.4 versus 7.8 per 100 person years, $\mathrm{RR}=0.18,95 \% \mathrm{CI}=0.04-0.83)$; it was noted that recurrent TB occurred only in individuals who had symptomatic HIV disease before their initial diagnosis of TB. It seems likely that secondary preventive therapy against TB would be beneficial in areas where the risk of TB infection is high. Further clarification of who would benefit and the optimum duration of therapy (fixed or lifelong) would be valuable, particularly in view of the large number of potentially eligible HIV-infected individuals. Secondary TB preventive therapy is less likely to be useful in regions where TB prevalence is lower and the risk of reinfection is correspondingly smaller.

Conclusions. Implementation of $T B$ preventive therapy. TB preventive therapy is effective against the most important HIV-related disease in sub-Saharan Africa, and should be implemented where feasible. The top priority for National TB Control Programs remains the detection and treatment of active cases of $\mathrm{TB}$, and the implementation of preventive therapy should not be at the expense of this goal. However, case detection and treatment is proving inadequate to control TB in countries with high HIV prevalence. ${ }^{41}$ Preventive therapy may be an important part of a broader program necessary to interrupt TB transmission in countries severely affected by the HIV epidemic, but it would probably have to be used very widely to achieve a significant public health benefit.

A major barrier to implementing preventive therapy is the identification of asymptomatic HIV-infected individuals who would benefit from this treatment. As a first step, opportunities to implement preventive therapy need to be sought within health structures where HIV counseling and testing is already being provided. This intervention could have wider benefits, since the availability of effective treatment may provide an incentive for people to attend for voluntary counseling and testing for HIV (Godfrey-Faussett P and others, unpublished data). Existing services providing care for HIVinfected individuals are in an ideal position to implement TB preventive therapy. Other services that routinely provide voluntary counseling and testing, such as antenatal services, might be able to initiate TB preventive therapy. Further opportunities could be created in occupational health settings, since TB prevention could be cost-beneficial to employers. Assurance of confidentiality would be crucial.

Research priorities. Research priorities to enable the successful translation of TB preventive therapy to operational practice include studies determining how best to detect active TB among individuals potentially eligible for preventive therapy. Studies are needed to determine the optimum duration of TB preventive therapy, comparing the current standard of six- or nine-month regimens with indefinite preventive therapy; two such studies are due to start in South Africa and Botswana. Studies to evaluate effectiveness under operational conditions are required; these will also need to measure adherence to treatment. Resistance to antitubercu- 
lous drugs should be monitored. Other important areas include ways to promote and sustain adherence to preventive therapy.

\section{PREVENTING OPPORTUNISTIC INFECTIONS WITH COTRIMOXAZOLE}

What we know. In industrialized countries, the earliest improvements in survival with HIV infection were due to improved treatment for common opportunistic infections and the introduction of cotrimoxazole as preventive therapy against PCP. ${ }^{42}$ Since PCP is far less common among adults in most African countries than in the United States and Europe ${ }^{43}$ it was uncertain whether cotrimoxazole would be a useful intervention for African populations. However, some of the major causes of illness and death such as bacterial infections (particularly nontyphoid salmonellosis and pneumococcal disease) and cerebral toxoplasmosis are potentially preventable using cotrimoxazole, which is inexpensive and widely available in many low-income countries. Trials were therefore set up to evaluate the safety and efficacy of cotrimoxazole among HIV-infected people in African countries.

Efficacy of cotrimoxazole among HIV-infected populations in African countries. Two large placebo-controlled studies have examined the efficacy of cotrimoxazole ( $960 \mathrm{mg}$ a day) in African populations, both conducted in Abidjan, Côte d'Ivoire. Wiktor and others recruited HIV-infected individuals with newly diagnosed pulmonary TB (at least WHO stage 3) from TB clinics. ${ }^{44}$ The main outcome measures were hospitalization or death from any cause. In a simultaneous study by Anglaret and others, HIV-infected individuals in WHO stage 2 or 3 (i.e., symptomatic disease, including pulmonary TB, but excluding those with major opportunistic infections) were recruited from community clinics. ${ }^{45}$ The main outcome measure was the "severe event" rate; i.e., death or hospitalization from any cause.

The main results of these studies are compared in Table 4. In the study of Wiktor and others, ${ }^{44}$ both the hospitalization rate and the mortality rate were significantly reduced in the cotrimoxazole group (rate ratio for hospitalization $=$ $0.57,95 \% \mathrm{CI}=0.36-0.90$; hazard ratio for mortality $=0.54$, $95 \% \mathrm{CI}=0.38-0.77$ ). The effect on mortality rate was only seen in those with baseline CD4 counts less than $350 \times 10^{6} /$ L. In the study of Anglaret and others, ${ }^{45}$ severe events were significantly reduced in the cotrimoxazole group (hazard ratio $=0.57,95 \% \mathrm{CI}=0.43-0.75)$. Most of the severe events were hospitalizations, and there was no significant difference in the mortality rate (hazard ratio $=0.87,95 \% \mathrm{CI}=0.57$ 1.32). There was a significant difference in the event rates between cotrimoxazole and placebo groups in all three strata of baseline CD4 count (number of persons with severe events: CD4 > $500 \times 10^{6} / \mathrm{L}: 6$ versus 21 , hazard ratio $=0.27$ [95\% CI $=0.11-0.68]$; CD4 200-499 $\times 10^{6} / \mathrm{L}: 31$ versus 39 , hazard ratio $=0.55[95 \% \mathrm{CI}=0.34-0.88] ; \mathrm{CD} 4<200$ $\times 10^{6} / \mathrm{L}: 47$ versus 64 , hazard ratio $=0.66[95 \% \mathrm{CI}=0.45-$ 0.97]).

The two studies were similar in showing a significant reduction in morbidity in the cotrimoxazole group. However they differed in that only the study of Wiktor and others found a significantly reduced mortality rate in the group receiving cotrimoxazole. Furthermore, the study of Anglaret and others found cotrimoxazole to have a beneficial effect at all levels of baseline CD4 count, whereas the study of Wiktor and others found benefit only in subgroups with a CD4 count less than $350 \times 10^{6} / \mathrm{L}$ at study entry.

How can these differences be explained? Patients in the study of Wiktor and others might have had more advanced disease (all had pulmonary TB, at least WHO stage 3) than those in the study of Anglaret and others (WHO stage 2 or $3)$. However, because the baseline CD4 count was almost identical in the two study populations, and the mortality rates were similar in the control groups of the two studies, this seems unlikely. The higher hospitalization rate in the study of Anglaret and others was probably due to inclusion of less severe events than in the study of Wiktor and others. In the study of Anglaret and others, hospitalizations included admissions to a dedicated study day-care center, whereas in the study of Wiktor and others, patients requiring hospitalization were referred to one of the university hospitals. This is supported by the causes of morbidity identified. In the study of Anglaret and others, the most frequent severe events were nonspecific enteritis, herpes zoster, and acute unexplained fever; these events would not necessarily have led to hospitalization in the study of Wiktor and others. If the study of Anglaret and others "captured" more minor illness, such as malaria, this may explain why cotrimoxazole was found to reduce morbidity at all CD4 counts in this study but not in the study of Wiktor and others.

The absence of a significant effect on mortality rates in the study of Anglaret and others could have been due to lack of statistical power, since this study was not designed to detect a difference in mortality rates. Given the observed mortality rates, the study had only about $32 \%$ power to detect a statistically significant difference at the 5\% level.

An important finding of both studies was that cotrimoxazole was well tolerated with very few serious adverse events. In the study of Anglaret and others, three adverse events were deemed "probably" due to cotrimoxazole, only two of which led to discontinuation of the drug (because of rash). There was a significant excess of neutropenia (mostly mild or moderate) in the cotrimoxazole group. In the study of Wiktor and others, adverse events were more frequent in the placebo than the cotrimoxazole group, and permanent discontinuation of study medication was required in $2.7 \%$ of the patients in both the cotrimoxazole and placebo groups. This supports previous observational data reporting a low incidence of cutaneous reactions to cotrimoxazole in HIVinfected African individuals. ${ }^{46}$

Two other studies support the usefulness of cotrimoxazole or similar therapy among HIV-infected individuals. In an open randomized controlled trial, daily isoniazid plus weekly sulfadoxine-pyrimethamine was compared with no treatment among 263 HIV-infected patients who had completed treatment for pulmonary TB in Abidjan. ${ }^{39}$ Symptoms were less frequent in the intervention group (rate ratio $=0.35,95 \%$ $\mathrm{CI}=0.31-0.4)$ as were "sick days" (rate ratio $=0.21,95 \%$ $\mathrm{CI}=0.13-0.34)$, although the reduction in mortality rates was not statistically significant (rate ratio $=0.64,95 \% \mathrm{CI}$ $=0.35-1.17)$. Part of the reduction in morbidity was due to a reduction in TB incidence, but the number of $\mathrm{TB}$ events was relatively small (4 versus 10), suggesting that sulfadoxine-pyrimethamine probably contributed to the reduction in morbidity. Further support comes from an observational 
study from Cape Town, South Africa, in which 71 HIVinfected patients with TB and CD4 counts $<200 \times 10^{6} / \mathrm{L}$ who received cotrimoxazole (480 $\mathrm{mg}$ a day) were compared with historical controls. ${ }^{47}$ The incidence of cotrimoxazolepreventable disease ( $\mathrm{PCP}$, cerebral toxoplasmosis, nontyphoid salmonellosis, bacterial pneumonia) was significantly lower in the cotrimoxazole group (rate ratio $=0.23,95 \% \mathrm{CI}$ $=0.06-0.84$ ), and mortality rates were also significantly reduced.

Other trials of cotrimoxazole as prophylaxis against HIVrelated disease were started in Senegal (Maynart M and others, unpublished data), Malawi, and South Africa, but recruitment to the placebo-controlled phase was stopped (when the results of the Abidjan studies were released) before definitive results were reached. In Malawi and South Africa, the intervention groups are being compared with historical controls (Zijlstra EE and others, unpublished data; Churchyard $\mathrm{G}$ and others, unpublished data), and operational evaluations are in progress in Malawi (Zachariah $\mathrm{R}$ and others, unpublished data) and South Africa (Grant AD and others, unpublished data; Hausler $\mathrm{H}$ and others, unpublished data).

In conclusion, the Abidjan studies provide convincing evidence that cotrimoxazole preventive therapy is well-tolerated and results in clinically important reductions in morbidity and mortality rates among West African people with symptomatic HIV disease. The report from Cape Town suggests that it may also be of benefit in other African populations.

What we don't know. The most important question is whether the results of the randomized controlled trials from Abidjan can be generalized to other regions in sub-Saharan Africa. The results may not be applicable elsewhere because of regional differences in, first, the spectrum of HIV-related disease, and, second, the prevalence of resistance of relevant pathogens to cotrimoxazole.

Differences in spectrum of HIV-related disease. To predict whether cotrimoxazole will be effective in other parts of Africa, we need to consider what diseases were prevented in the published studies. In the study of Wiktor and others, cotrimoxazole resulted in a statistically significant reduction in the incidence of hospitalization attributed to enteritis due to isosporiasis and nontyphoid salmonella, and to nontyphoid salmonella septicemia. The incidence of hospitalization due to bacterial chest infections, anemia, urinary tract infections, and cerebral toxoplasmosis was lower in the group receiving cotrimoxazole, but the number of events in each category was small and the difference was not statistically significant. In the study of Anglaret and others, there was a significant reduction in hospitalization due to bacterial pneumonia, malaria, isosporiasis, and acute unexplained fever. Thus, cotrimoxazole may be expected to be effective in regions where these diseases are major causes of HIV-related morbidity and mortality.

The spectrum of disease as reported from Kenya is broadly similar to that in Côte d'Ivoire. There are very few comparable data available from southern Africa, but in South Africa there may be proportionally less diarrheal disease, salmonellosis, and toxoplasmosis (Corbett E and others, unpublished data). It is therefore uncertain whether cotrimoxazole will be beneficial in this region, although the study from Cape Town suggests that it may be.
Resistance to cotrimoxazole. Another issue determining the effectiveness of cotrimoxazole as preventive therapy is the prevalence of cotrimoxazole resistance among relevant bacterial pathogens, in particular nontyphoid salmonellae and pneumococci. The prevalence of cotrimoxazole resistance among enterobacteriacae in Abidjan is relatively low; in an earlier study, the prevalence of cotrimoxazole resistance among nontyphoid salmonellae in 1995 was $14 \% .^{48}$ This compares with $46 \%$ in Kenya in 1993-1994 ${ }^{49}$ and $83 \%$ in Malawi in 1998,50 and $39 \% \%^{51}$ and $90 \%{ }^{52}$ among Salmonella spp. in Ethiopia during 1995 and in 1994-1996, respectively.

Among isolates of Streptococcus pneumoniae, there is also considerable regional variation in antibiotic resistance patterns. Comparisons are complicated by differences in the prevalence of resistance between adults and children, between invasive and noninvasive isolates, and by differences in the method used to determine resistance. The reported prevalence of resistance to cotrimoxazole varies widely, reported at 54\% among invasive organisms in Kenyan adults, ${ }^{53}$ $91 \%$ in Malawi in 1998 (population not specified), ${ }^{50}$ and $10 \%$ among invasive organisms in South African adults. ${ }^{54}$ Published data from Côte d'Ivoire are sparse; during 1994$1996,73 \%$ of 11 invasive $S$. pneumoniae isolates from adult inpatients were resistant to cotrimoxazole. ${ }^{48}$

These data suggest that cotrimoxazole may be less effective in preventing nontyphoid salmonellae in African countries outside Côte d'Ivoire, particularly in southern and eastern Africa, and the effect on pneumococcal disease is uncertain. However, no data confirm whether in vitro resistance correlates with lack of effectiveness in vivo, and the data from South Africa mentioned earlier provide some cause for optimism.

Who should receive cotrimoxazole? The two large trials of cotrimoxazole leave some uncertainty about who should receive cotrimoxazole. Patients with TB may benefit more from cotrimoxazole than other HIV-infected individuals, because while they are being treated, they are no longer at risk for $\mathrm{TB}$, thus removing a major cause of morbidity and mortality that is not amenable to prevention with cotrimoxazole. Among individuals in WHO stage 2 and 3, cotrimoxazole reduced morbidity, perhaps due to conditions that were less severe but probably important in terms of quality of life and working capacity. Since neither study evaluated individuals in WHO stage 4, there is no specific evidence that cotrimoxazole is beneficial in this group, although this seems highly likely, because in the study of Wiktor and others the protective effect of cotrimoxazole increased with decreasing CD4 count.

Conclusions. Implementation of cotrimoxazole preventive therapy. Since cotrimoxazole reduced morbidity and mortality in the studies from Abidjan, it should be implemented among individuals with symptomatic HIV disease, particularly those with TB, in situations where the spectrum of HIVrelated disease and resistance patterns suggest that it is likely to be effective. This could be implemented through TB control programs and existing HIV clinics. As with TB preventive therapy, a first step would be to seek other opportunities to implement cotrimoxazole preventive therapy within health care systems where HIV counseling and testing is already available. 
Asymptomatic individuals (i.e., WHO stage 1) were not included in any of these studies; therefore, there is no evidence to guide a decision concerning when cotrimoxazole should be started in African countries. It would also be useful to be able to "target" preventive therapy to those most likely to benefit. One approach might be use trial data to derive "numbers needed to treat" to prevent specified outcomes at different baseline CD4 counts. For example, using mortality rates from the study of Wiktor and others, the number of people needed to receive treatment with cotrimoxazole for one year to prevent one death would be 1.5, 7, 6, and 77 for CD4 counts 0-99, 100-199, 200-349, and $>350$ $\times 10^{6} / \mathrm{L}$, respectively. Clearly, in the majority of resourcepoor settings CD4 counts are not available; thus, a surrogate such as total lymphocyte count would need to be used.

In regions where the effectiveness of cotrimoxazole is uncertain because of a high prevalence of cotrimoxazole resistance or differences in the spectrum of HIV-related disease, the situation is less clear. Since cotrimoxazole is safe and inexpensive, it would be appropriate to implement in situations where it is likely to be of benefit. It will be important to find ways of assessing and monitoring its effectiveness; this could be done by means of incremental introduction, historical comparisons, or case-control studies. Where it is uncertain whether cotrimoxazole will have significant beneficial effects, further trials may be appropriate.

Research priorities. The effectiveness of cotrimoxazole under operational conditions is unknown and will need to be evaluated. As with TB preventive therapy, adherence is likely to be a key determinant of effectiveness, and practical ways of promoting and monitoring adherence need to be found. The effect of long-term low-dose cotrimoxazole on antibiotic resistance patterns should be monitored. Widespread use of cotrimoxazole preventive therapy is likely to result in an increase in cotrimoxazole resistance, ${ }^{55}$ which will require monitoring, and ultimately alternative agents may need to be identified.

\section{PREVENTING PNEUMOCOCCAL DISEASE}

What we know. Pneumococcal polysaccharide vaccine (PPV) was first evaluated among military personnel in the $1940 \mathrm{~s}^{56}$ and mineworkers in South Africa in the 1970s, ${ }^{57}$ and was found to be highly effective in preventing pneumococcal pneumonia in these immunocompetent populations. As the prevalence of antibiotic resistance among pneumococci increases, ${ }^{58}$ vaccination becomes a more attractive intervention since it does not depend on adherence to medication and does not promote antibiotic resistance. Pneumococcal disease is an important cause of HIV-related morbidity and mortality in African populations. ${ }^{59}$ The Centers for Disease Control and Prevention "generally recommend" PPV for HIV-infected persons, ${ }^{60}$ although the evidence of efficacy in this group comes from observational studies in the United States, ${ }^{61-63}$ not randomized controlled trials. Interestingly, one of these studies found reduced vaccine effectiveness in African Americans for reasons that were not clear. ${ }^{63}$

With this background, the results of a randomized controlled trial of PPV among HIV-infected Ugandan adults are of particular interest. 23-valent PPV was compared with placebo among 1,392 HIV-infected Ugandan adults in WHO stages 1-3, using invasive pneumococcal disease as the primary endpoint. ${ }^{64}$ Approximately $44 \%$ of the population had CD4 cell counts $<200 \times 10^{6} / \mathrm{L}$ at study entry. There was no difference in mortality between the vaccine and placebo groups: 185 versus 182 deaths, unadjusted hazard ratio = $0.99(95 \% \mathrm{CI}=0.80-1.21)$. There was a nonsignificant excess of first episodes of invasive pneumococcal disease in the vaccine group: 15 versus 10 events, hazard ratio $=1.47$ $(95 \% \mathrm{CI}=0.7-3.3)$, and a significant excess of all-cause pneumonia in the vaccine group: 40 versus 21 events, hazard ratio $=1.89(95 \% \mathrm{CI}=1.1-3.2)$. This suggests that PPV has no protective effect in this population and may have resulted in an increase in episodes of pneumonia.

There are a number of possible explanations for the lack of efficacy of this intervention. First, the pneumococcal serogroups causing disease in the study population might have been different from the serotypes included in the 23-valent vaccine used in the trial. However, this is unlikely since $85 \%$ of invasive isolates of pneumococci in study participants were with serogroups included in the vaccine. Second, the vaccine may have failed to induce protective immunity in the study participants, as has been found previously in HIVinfected individuals. ${ }^{65}$ Almost half of the study population had severe immunosuppression; although there were too few events to detect a difference in efficacy by CD4 count, the lack of efficacy is consistent with work showing impaired immune responses to PPV in HIV-infected individuals with low CD4 counts. ${ }^{66}$ However, these studies are difficult to interpret because antibody responses may not correlate with clinical protection. Third, the researchers suggest that the vaccine may have caused destruction of polysaccharide-responsive B cell clones.

We can conclude that PPV is not beneficial in HIV-infected individuals in this African population, where most participants were already immunosuppressed. Since most HIV-infected people in low-income countries make first contact with health services when they already have advanced immunosuppression, this intervention is unlikely to be useful in this setting.

What we don't know. New vaccines to prevent pneumococcal disease are becoming available which may be more effective in HIV-infected and other "high-risk" populations. Polysaccharide antigens induce antibodies independent of $\mathrm{T}$ cell function, and the immune response is therefore restricted. They do not induce immunologic memory or maturation of the immune response, and the response is unreliable in children younger than two years old, the elderly, or immunocompromised individuals. To enhance immunogenicity, conjugate vaccines have been developed in which the polysaccharide antigen is linked to a protein carrier.

Conjugate vaccines against Haemophilus influenzae type b (Hib) have been highly successful in reducing the incidence of invasive Hib infections in infants. Pneumococcal conjugate vaccines have been shown to be immunogenic among children, including those with HIV infection ${ }^{67}$ and efficacy studies in children are in progress in South Africa and The Gambia. Conjugate vaccines may also hold promise for HIV-infected adults and need to be evaluated. If effective, the major obstacle to be overcome would be their price, which is currently prohibitively expensive for use in lowincome countries. 
Conclusions. On the basis of current evidence, PPV cannot be recommended for HIV-infected people in African countries. Conjugate vaccines, or strategies combining both types of vaccine, need to be evaluated.

\section{PREVENTING FUNGAL DISEASE}

Cryptococcal disease seems to be an important cause of HIV-related morbidity and mortality in African countries; it may be more significant in eastern and southern Africa. Esophageal candidiasis is also reported as a major cause of morbidity. Fungal disease can be prevented; in a randomized controlled trial in the United States, primary preventive therapy with fluconazole was shown to reduce the incidence of cryptococcal disease, esophageal candidiasis, and superficial fungal infections among HIV-infected individuals, particularly those with CD4 counts less than $50 \times 10^{6} / \mathrm{L} .{ }^{68}$ Fluconazole had no significant effect on mortality in this study, perhaps because of lack of statistical power to detect a difference; mortality rates attributable to fungal disease were low, and the study was not designed to address this issue.

In spite of its efficacy, primary preventive therapy with fluconazole is not generally recommended as standard of care in the United States because of the low incidence of disease, the lack of survival benefit, the risk of promoting resistance to antifungal drugs, and the toxicity and cost of imidazole therapy. ${ }^{60}$ The burden of cryptococcal disease may be more significant in some regions of Africa. However, in many countries the current cost of imidazoles is so high that even symptomatic cryptococcal disease is not treated. In this situation, preventive therapy with imidazoles is unlikely to be affordable or cost-effective. However, if generic imidazoles become available, the price may fall substantially ${ }^{69}$ and antifungal preventive therapy could be worth further consideration in countries where cryptococcal disease is a major cause of morbidity and mortality.

\section{CONCLUSIONS}

Using drugs that are widely available and relatively inexpensive, preventive therapy can reduce the incidence of some of the most important HIV-related diseases relevant to people in African countries. Optimum regimens will vary geographically, and regional guidelines for preventive therapy need to be established. Opportunities need to be sought to implement these regimens within existing health services, particularly those where HIV counseling and testing is currently offered. Other opportunities could be created, for example, within occupational health settings and among students and the military. The effectiveness of these preventive interventions under operational conditions will need to be determined. Other priorities in the management of HIV-related disease include providing essential drugs and improving palliative care.

The best way to prevent HIV-related disease in sub-Saharan African countries is to prevent new HIV infections, and to provide effective antiretroviral therapy, although the implementation of the latter poses a huge challenge. Preventive therapies represent an opportunity to reduce morbidity and prolong healthy life that could now be offered to many HIV-infected people in low-income countries, and could, if widely implemented, have significant impact on morbidity at the population level. Furthermore, the availability of effective and affordable regimens to prevent HIV-related disease may encourage people to seek HIV testing and may help overcome the sense of powerlessness in countries where the HIV epidemic has hit hardest.

\section{Addendum:}

Since the submission of this article, the trial of cotrimoxazole versus placebo among HIV-infected adults in Senegal has been published: there was no difference in morbidity and mortality between the two groups. ${ }^{71}$ Recruitment to the study was terminated early when the results of the study by Anglaret and others ${ }^{45}$ were released, and so the number of participants was lower than planned, resulting in low study power. In addition, an observational study from South Africa has been published in which morbidity and survival were compared between patients receiving cotrimoxazole and those not given cotrimoxazole. ${ }^{72}$ Among individuals in WHO stages 3 and 4, morbidity was reduced and survival increased among those receiving cotrimoxazole. However, among individuals in WHO stage 2 or with a CD4 count of $200-500 \times 10^{6} / \mathrm{L}$ there was no significant difference in morbidity or survival among those receiving cotrimoxazole. This was an observational cohort study, not a randomized controlled trial, and therefore there may have been differences between the two groups which were not controlled for. However, the results suggest that the maximum benefit from cotrimoxazole is among individuals with advanced HIV disease.

Authors' addresses: Alison D. Grant, Clinical Research Unit, London School of Hygiene and Tropical Medicine, Keppel Street, London WC1E 7HT, United Kingdom. Jonathan E. Kaplan, Division of HIV/AIDS Prevention, Centers for Disease Control and Prevention, 1600 Clifton Road NE, Atlanta, GA 30333. Kevin M. De Cock, Centers for Disease Control and Prevention, US Embassy, PO Box 30137, Nairobi, Kenya.

\section{REFERENCES}

1. UNAIDS, 2000. AIDS epidemic update: December 2000. Geneva: UNAIDS/WHO, UNAIDS/00.44E-WHO/CDS/CSR/ EDC/2000.9.

2. Grant AD, Djomand G, Smets P, Kadio A, Coulibaly M, Kakou A, Maurice C, Whitaker JP, Sylla-Koko F, Bonard D, Wiktor SZ, Hayes RJ, De Cock KM, Greenberg AE, 1997. Profound immunosuppression across the spectrum of opportunistic disease among hospitalised HIV-infected adults in Abidjan, Côte d'Ivoire. AIDS 11: 1357-1364.

3. Kassa E, Rinke de Wit TF, Hailu E, Girma M, Messele T, Gebre Mariam H, Yohannes S, Jurriaans S, Yeneneh H, Coutinho RA, Fontanet AL, 1999. Evaluation of the World Health Organization staging system for HIV infection and disease in Ethiopia: association between clinical stages and laboratory markers. AIDS 13: 381-389.

4. Kaplan JE, Hu DJ, Holmes KK, Jaffe HW, Masur H, De Cock KM, 1996. Preventing opportunistic infections in human immunodeficiency virus-infected persons: implications for the developing world. Am J Trop Med Hyg 55: 1-11.

5. Grant AD, De Cock KM, 1998. The growing challenge of HIV/ AIDS in developing countries. Br Med Bull 54: 369-381.

6. Wood R, O'Keefe EA, Maartens G, 1996. The changing pattern of transmission and clinical presentation of HIV infection in the Western Cape region of South Africa (1984-1995). S Afr J Epidemiol Infect 11: 96-98.

7. Gilks CF, Brindle RJ, Otieno LS, Simani PM, Newnham RS, 
Bhatt SM, Lule GN, Okelo GBA, Watkins WM, Waiyaki PG, Were JBO, Warrell DA, 1990. Life-threatening bacteraemia in HIV-1 seropositive adults admitted to hospital in Nairobi, Kenya. Lancet 336: 545-549.

8. Gilks CF, Brindle RJ, Otieno LS, Bhatt SM, Newnham RS, Simani PM, Lule GN, Okelo GBA, Watkins WM, Waiyaki PG Were JOB, Warrell DA, 1990. Extrapulmonary and disseminated tuberculosis in HIV-1-seropositive patients presenting to the acute medical services in Nairobi. AIDS 4: 981-985.

9. Grant AD, Sidibé K, Domoua K, Bonard D, Sylla-Koko F, Dosso M, Yapi A, Maurice C, Whitaker JP, Lucas SB, Hayes RJ, Wiktor SZ, De Cock KM, Greenberg AE, 1998. Spectrum of disease among HIV-infected adults hospitalised in a respiratory medicine unit in Abidjan, Côte d'Ivoire. Int $J$ Tuberc Lung Dis 2: 926-934.

10. Archibald LK, den Dulk MO, Pallangyo KJ, Reller LB, 1998. Fatal Mycobacterium tuberculosis bloodstream infections in febrile hospitalized adults in Dar es Salaam, Tanzania. Clin Infect Dis 26: 290-296.

11. Ssali FN, Kamya MR, Wabwire-Mangen F, Kasasa S, Joloba M, Williams D, Mugerwa RD, Ellner JJ, Johnson JL, 1998. A prospective study of community-acquired bloodstream infections among febrile adults admitted to Mulago Hospital in Kampala, Uganda. J Acquir Immune Defic Syndr Hum Retrovirol 19: 484-489.

12. Vugia DJ, Kiehlbauch JA, Yeboue K, N'Gbichi JM, Lacina D, Maran M, Gondo M, Kouadio K, Kadio A, Lucas SB, Kestens L, Crawford JT, Wells JG, Brattegaard K, De Cock KM, Griffin PM, 1993. Pathogens and predictors of fatal septicemia associated with human immunodeficiency virus infection in Ivory Coast, West Africa. J Infect Dis 168: 564-570.

13. Taelman H, Clerinx J, Kagame A, Batungwanayo J, Nyirabareja A, Bogaerts J, 1991. Cryptococcosis, another growing burden for central Africa (letter). Lancet 338: 761.

14. Heyderman RS, Gangaidzo IT, Hakim JG, Mielke J, Taziwa A, Musvaire P, Robertson V, Mason PR, 1998. Cryptococcal meningitis in human immunodeficiency virus-infected patients in Harare, Zimbabwe. Clin Infect Dis 26: 284-289.

15. Okongo M, Morgan D, Mayanja B, Ross A, Whitworth J, 1998. Causes of death in a rural, population-based human immunodeficiency virus type 1 (HIV1) natural history cohort in Uganda. Int J Epidemiol 27: 698-702.

16. Lucas SB, Hounnou A, Peacock C, Beaumel A, Djomand G, N'Gbichi J-M, Yeboue K, Hondé M, Diomande M, Giordano C, Doorly R, Brattegaard K, Kestens L, Smithwick R, Kadio A, Ezani N, Yapi A, De Cock KM, 1993. The mortality and pathology of HIV infection in a West African city. AIDS 7: 1569-1579.

17. Mocroft A, Vella S, Benfield TL, Chiesi A, Miller V, Gargalianos P, d'Arminio Monforte A, Yust I, Bruun JN, Phillips AN, Lundgren JD, for the EuroSIDA Study Group, 1998. Changing patterns of mortality across Europe in patients infected with HIV-1. Lancet 352: 1725-1730.

18. Pape JW, Jean SS, Ho JL, Hafner A, Johnson WD Jr, 1993. Effect of isoniazid prophylaxis on incidence of active tuberculosis and progression of HIV infection. Lancet 342: 268272.

19. Hawken MP, Meme HK, Elliott LC, Chakaya JM, Morris JS, Githui WA, Juma ES, Odhiambo JA, Thiong'o LN, Kimari JN, Ngugi EN, Bwayo JJ, Gilks CF, Plummer FA, Porter JDH, Nunn PP, McAdam KPWJ, 1997. Isoniazid preventive therapy for tuberculosis in HIV-1-infected adults: results of a randomized controlled trial. AIDS 11: 875-882.

20. Whalen CC, Johnson JL, Okwera A, Hom DL, Huebner R, Mugyenyi P, Mugerwa RD, Ellner JJ, for the Uganda-Case Western Reserve University Research Collaboration, 1997. A trial of three regimens to prevent tuberculosis in Ugandan adults infected with the human immunodeficiency virus. $N$ Engl $J$ Med 337: 801-808.

21. Gordin FM, Matts JP, Miller C, Brown LS, Hafner R, John SL, Klein M, Vaughn A, Besch CL, Perez G, Szabo S, El-Sadr $\mathrm{W}$, for the Terry Beirn Community Programs for Clinical Research on AIDS, 1997. A controlled trial of isoniazid in persons with anergy and human immunodeficiency virus infec- tion who are at high risk for tuberculosis. N Engl J Med 337: 315-320.

22. Mwinga A, Hosp M, Godfrey-Faussett P, Quigley M, Mwaba P, Mugala BN, Nyirenda O, Luo N, Pobee J, Elliott AM, McAdam KPWJ, Porter JDH, 1998. Twice weekly tuberculosis preventive therapy in HIV infection in Zambia. AIDS 12: 2447-2457.

23. Wilkinson D, Squire SB, Garner P, 1998. Effect of preventive treatment for tuberculosis in adults infected with HIV: systematic review of randomised placebo controlled trials. $\mathrm{Br} \mathrm{Med}$ J 317: 625-629.

24. Bucher HC, Griffith LE, Guyatt GH, Sudre P, Naef M, Sendi P, Battegay M, 1999. Isoniazid prophylaxis for tuberculosis in HIV infection: a meta-analysis of randomized controlled trials. AIDS 13: 501-507.

25. Hawken MP, Muhindi DW, 1999. Tuberculosis preventive therapy in HIV-infected persons: feasibility issues in developing countries. Int J Tuberc Lung Dis 3: 646-650.

26. World Health Organization Global Tuberculosis Program, UNAIDS, 1998. Policy Statement on Preventive Therapy Against Tuberculosis in People Living with HIV. Geneva: WHO, WHO/TB/98.255.

27. International Union Against Tuberculosis Committee on Prophylaxis, 1982. Efficacy of various durations of isoniazid preventive therapy for tuberculosis: five years of follow-up in the IUAT trial. Bull World Health Organ 60: 555-564.

28. Snider DE, Caras GJ, Koplan JP, 1986. Preventive therapy with isoniazid: cost-effectiveness of different durations of therapy. JAMA 255: 1579-1583.

29. American Thoracic Society, 2000. Targeted tuberculin testing and treatment of latent tuberculosis infection. Am J Respir Crit Care Med 161: S221-S247.

30. Godfrey-Faussett P, Githui W, Batchelor B, Brindle R, Paul J, Hawken M, Gathua S, Odhiambo J, Ojoo S, Nunn P, 1994. Recurrence of HIV-related tuberculosis in an endemic area may be due to relapse or reinfection. Tuberc Lung Dis 75: 199-202.

31. Godfrey-Faussett P, Sonnenberg P, Shearer S, Bruce MC, Mee C, Morris L, Murray J, 2000. Tuberculosis control and molecular epidemiology in a South African gold-mining community. Lancet 356: 1066-1071.

32. Halsey NA, Coberly JS, Desormeaux J, Losikoff P, Atkinson J, Moulton LH, Contave M, Johnson M, Davis H, Geiter L, Johnson E, Huebner R, Boulos R, Chaisson RE, 1998. Randomised trial of isoniazid versus rifampicin and pyrazinamide for prevention of tuberculosis in HIV-1 infection. Lancet 351: $786-792$.

33. O'Brien RJ, Perriëns JH, 1995. Preventive therapy for tuberculosis in HIV infection: the promise and the reality. AIDS 9: 665-673.

34. Aisu T, Raviglione MC, van Praag E, Eriki P, Narain JP, Barugahare L, Tembo G, McFarland D, Engwau FA, 1995. Preventive chemotherapy for HIV-associated tuberculosis in Uganda: an operational assessment at a voluntary counselling and testing centre. AIDS 9: 267-273.

35. Pablos-Méndez A, Raviglione MC, Laszlo A, Binkin N, Rieder HL, Bustreo F, Cohn DL, Lambregts-van Weezenbeek CSB, Kim SJ, Chaulet P, Nunn P, for the World Health Organization-International Union against Tuberculosis and Lung Disease Working Group on Anti-Tuberculosis Drug Resistance Surveillance, 1998. Global surveillance for antituberculous drug resistance 1994-1997. N Engl J Med 338: 1641-1649.

36. Foster SD, Godfrey-Faussett P, Porter J, 1997. Modelling the economic benefits of tuberculosis preventive therapy for people with HIV: the example of Zambia. AIDS 11: 919-925.

37. Masobe P, Lee T, Price M, 1995. Isoniazid prophylactic therapy for tuberculosis in $\mathrm{HIV}$-seropositive patients-a least-cost analysis. S Afr Med J 85: 75-81.

38. Perriëns JH, St. Louis ME, Mukadi YB, Brown C, Prignot J, Pouthier F, Portaels F, Willame J-C, Mandala JK, Kaboto M, Ryder RW, Roscigno G, Piot P, 1995. Pulmonary tuberculosis in HIV-infected patients in Zaire: a controlled trial of treatment for either 6 or 12 months. N Engl J Med 332: 779-784.

39. Haller L, Sossouhounto R, Coulibaly I-M, Dosso M, Koné M, 
Adom H, Meyer UA, Betschart B, Wenk M, Haefeli WE, Lobognon LR, Porquet M, Kaboré G, Sorenson F, Reber-Liske R, Stürchler D, 1999. Isoniazid plus sulphadoxine-pyrimethamine can reduce morbidity of HIV-positive patients treated for tuberculosis in Africa: a controlled clinical trial. Chemotherapy 45: 452-465.

40. Fitzgerald DW, Desvarieux M, Severe P, Joseph P, Johnson WD Jr, Pape JW, 2000. Effect of post-treatment isoniazid on prevention of recurrent tuberculosis in HIV-1-infected individuals: a randomised trial. Lancet 356: 1470-1474.

41. De Cock KM, Chaisson RE, 1999. Will DOTS do it? A reappraisal of tuberculosis control in countries with high rates of HIV infection. Int J Tuberc Lung Dis 3: 457-465.

42. Chaisson RE, Keruly J, Richman DD, Moore RD, the Zidovudine Epidemiology Group, 1992. Pneumocystis prophylaxis and survival in patients with advanced human immunodeficiency virus infection treated with zidovudine. Arch Intern Med 152: 2009-2013.

43. Grant AD, Djomand G, De Cock KM, 1997. Natural history and spectrum of disease in adults with HIV/AIDS in Africa. AIDS 11: S43-S54.

44. Wiktor SZ, Sassan-Morokro M, Grant AD, Abouya L, Karon JM, Maurice C, Djomand G, Ackah A, Domoua K, Kadio A, Yapi A, Combe P, Tossou O, Roels T, Lackritz E, Coulibaly D, De Cock KM, Coulibaly I-M, Greenberg AE, 1999. Efficacy of trimethoprim-sulphamethoxazole prophylaxis to decrease morbidity and mortality in HIV-1-infected patients with tuberculosis in Abidjan, Côte d'Ivoire: a randomised controlled trial. Lancet 353: 1469-1475.

45. Anglaret X, Chêne G, Attia A, Toure S, Lafont S, Combe P, Manlan K, N'Dri-Yoman T, Salamon R, and the Cotrimo-CI study group, 1999. Early chemoprophylaxis with trimethoprim-sulphamethoxazole for HIV-1-infected adults in Abidjan, Côte d'Ivoire: a randomised trial. Lancet 353: $1463-$ 1468.

46. Colebunders R, Izaley L, Bila K, Kabumpangi K, Melameka N, Nyst M, Francis H, Curran JW, Ryder R, Piot P, 1987. Cutaneous reactions to trimethoprim-sulfamethoxazole in African patients with the acquired immunodeficiency syndrome. Ann Intern Med 107: 599-600.

47. Badri M, Maartens G, Wood R, Ehrlich R, 1999. Cotrimoxazole in HIV-1 infection. Lancet 354: 334-335.

48. Anglaret X, Sylla-Koko F, Bonard D, Combe P, Coulibaly M, Aoussi E, Dabis F, 1997. Susceptibilities to co-trimoxazole of pathogens isolated from blood and stool specimens in Abidjan, Ivory Coast, 1994-1996 (letter). J Clin Microbiol 35: 1915.

49. Kariuki S, Gilks C, Corkill J, Kimari J, Benea A, Waiyaki P, Hart CA, 1996. Multi-drug resistant non-typhi salmonellae in Kenya. J Antimicrob Chemother 38: 425-434.

50. Boeree MJ, Harries AD, Zijlstra EE, Taylor TE, Molyneux M, 1999. Co-trimoxazole in HIV-1 infection (letter). Lancet 354: 334.

51. Mache A, Mengistu Y, Cowley S, 1997. Salmonella serogroups identified from adult diarrhoeal out-patients in Addis Ababa, Ethiopia: antibiotic resistance and plasmid profile analysis. East Afr Med J 74: 183-186.

52. Aseffa A, Gedlu E, Asmelash T, 1997. Antibiotic resistance of prevalent Salmonella and Shigella strains in northwest Ethiopia. East Afr Med J 74: 708-713.

53. Scott JAG, Hall AJ, Muyodi C, Lowe B, Ross M, Chohan B, Mandaliya K, Getambu E, Gleeson F, Drobniewski F, Marsh $\mathrm{K}, 2000$. Aetiology, outcome and risk factors for mortality among adults with acute pneumonia in Kenya. Lancet 355: $1225-1230$.

54. Feldman C, Glatthaar M, Morar R, Mahomed MG, Kaka S, Cassel M, Klugman KP, 1999. Bacteremic pneumococcal pneumonia in HIV-seropositive and HIV-seronegative adults. Chest 116: 107-114.

55. Martin JN, Rose DA, Hadley WK, Perdreau-Remington F, Lam PK, Gerberding JL, 1999. Emergence of trimethoprim-sulfamethoxazole resistance in the AIDS era. J Infect Dis 180: $1809-1818$.

56. MacLeod CM, Hodges RG, Heidelberger M, Bernhard WG,
1945. Prevention of pneumococcal pneumonia by immunization with specific capsular polysaccharides. J Exp Med 82: $445-465$

57. Austrian R, Douglas RM, Schiffman G, 1977. Prevention of pneumococcal pneumonia by vaccination. Trans Assoc Am Physicians 89: 184-194.

58. Tomasz A, 1997. Antibiotic resistance in Streptococcus pneumoniae. Clin Infect Dis 24: S85-S88.

59. Gilks CF, Ojoo SA, Ojoo JC, Brindle RJ, Paul J, Batchelor BIF, Kimari JN, Newnham R, Bwayo J, Plummer FA, Warrell DA, 1996. Invasive pneumococcal disease in a cohort of predominantly HIV-1 infected female sex-workers in Nairobi, Kenya. Lancet 347: 718-723.

60. Centers for Disease Control and Prevention, 1999. 1999 USPHS/IDSA guidelines for the prevention of opportunistic infections in persons infected with human immunodeficiency virus. MMWR Morb Mortal Wkly Rep 48: 1-66.

61. Gebo K, Moore RD, Keruly JC, Chaisson RE, 1996. Risk factors for pneumococcal disease in human immunodeficiency virus-infected patients. J Infect Dis 173: 857-862.

62. Guerrero M, Kruger S, Saitoh A, Sorvillo F, Cheng K-J, French C, Beall G, 1999. Pneumonia in HIV-infected patients: a casecontrol survey of factors involved in risk and prevention. AIDS 13: 1971-1975.

63. Breiman RF, Keller DW, Phelan MA, Sniadack DH, Stephens DS, Rimland D, Farley MM, Schuchat A, Reingold AL, 2000. Evaluation of effectiveness of the 23-valent pneumococcal capsular polysaccharide vaccine for HIV-infected patients. Arch Intern Med 160: 2633-2638.

64. French N, Nakiyingi J, Carpenter LM, Lugada E, Watera C, Moi K, Moore M, Antvelink D, Mulder D, Janoff EN, Whitworth J, Gilks CF, 2000. 23-valent pneumococcal polysaccharide vaccine in HIV-1-infected Ugandan adults: double-blind, randomised and placebo controlled trial. Lancet 355: 2106-2111.

65. French N, Gilks CF, Mujugira A, Fasching C, O'Brien J, Janoff E, 1998. Pneumococcal vaccination in HIV-1-infected adults in Uganda: humoral response and two vaccine failures. AIDS 12: $1683-1689$.

66. Rodriguez-Barradas MC, Musher DM, Lahart C, Lacke C, Groover J, Watson D, Baughn R, Cate T, Crofoot G, 1992. Antibody to capsular polysaccharides of Streptococcus pneumoniae after vaccination of human immunodeficiency virusinfected subjects with 23-valent pneumococcal vaccine. $J$ Infect Dis 165: 553-556.

67. King JC, Vink PE, Farley JJ, Parks M, Smilie M, Madore D, Lichenstein R, Malinoski F, 1996. Comparison of the safety and immunogenicity of a pneumococcal conjugate with a licensed polysaccharide vaccine in human immunodeficiency virus and non-human immunodeficiency virus-infected children. Pediatr Infect Dis J 15: 192-196.

68. Powderly WG, Finkelstein DM, Feinberg J, Frame P, He W, van der Horst C, Koletar SL, Eyster ME, Carey J, Waskin H, Hooton TM, Hyslop N, Spector SA, Bozzette SA, 1995. A randomized trial comparing fluconazole with clotrimazole troches for the prevention of fungal infections in patients with advanced human immunodeficiency virus infection. $N$ Engl $J$ Med 332: 700-705.

69. Wilson D, Cawthorne P, Ford N, Aongsonwang S, 1999. Global trade and access to medicines: AIDS treatments in Thailand. Lancet 354: 1893-1895.

70. World Health Organization, 1990. Acquired immunodeficiency syndrome (AIDS): interim proposal for a WHO staging system for HIV infection and disease. Wkly Epidemiol Rec 65: 221-224.

71. Maynart M, Lièvre L, Salif Sow P, Kony S, Ngom Gueye NF, Bassène E, Metro A, Ndoye I, Sira Ba D, Coulaud JP, Costagliola D and the SIDAK Study Group, 2001. Primary prevention with cotrimoxazole for HIV-1-infected adults: results of the pilot study in Dakar, Senegal. J Acquir Immune Defic Syndr Hum Retrovirol 26: 130-136.

72. Badri M, Ehrlich R, Wood R, Maartens G, 2001. Initiating cotrimoxazole prophylaxis in HIV-infected patients in Africa: an evaluation of the provisional WHO/UNAIDS recommendations. AIDS 15: 1143-1148. 
APPENDIX 1

World Health Organization staging system for human immunodeficiency virus infection and disease (provisional ${ }^{70}$

Stage 1. Asymptomatic disease or persistent generalized lymphadenopathy.

Stage 2. $<10 \%$ weight loss; minor mucocutanous manifestations; Herpes zoster within the last 5 years; recurrent upper respiratory tract infections; and/or performance scale 2: symptomatic, normal activity.

Stage 3. Weight loss $>10 \%$; unexplained chronic fever or diarrhea $>1$ month; oral candidiasis; oral hairy leukoplakia; pulmonary tuberculosis within the past year; severe bacterial infections; and/or performance scale 3: bed-ridden $<50 \%$ of the day during the last month.

Stage 4. Human immunodeficiency virus (HIV) wasting syndrome; Pneumocystis carinii pneumonia; cerebral toxoplasmosis; cryptosporidiosis with diarrhea $>1$ month; cryptococcosis, extrapulmonary; cytomegalovirus disease of an organ other than liver, spleen or lymph nodes; Herpes simplex virus infection, mucocutaneous $>1$ month or visceral any duration; progressive multifocal leukoencephalopathy; disseminated endemic mycosis; candidiasis of esophagus, trachea, bronchi, or lungs; atypical mycobacteriosis, disseminated; nontyphoid Salmonella septicemia; extrapulmonary tuberculosis; lymphoma; Kaposi's sarcoma; HIV encephalopathy; and/or performance scale 4: bed-ridden $>50 \%$ of the day during the last month. 